\title{
Space Science and Technology Partnership Forum: Analysis for a Joint Demonstration of High Priority, In-Space Assembly Technology
}

\author{
Doris Hamill, ${ }^{1}$ Sharon A. Jefferies, ${ }^{2}$ Frederic H. Stillwagen, ${ }^{3}$ Robert W. Moses, ${ }^{4}$ \\ NASA Langley Research Center, Hampton, Virginia, 23681, USA \\ Carie Mullins $^{5}$, and Elaine Gresham ${ }^{6}$ \\ Bryce Space and Technology, City, State, Zip Code, Country
}

\begin{abstract}
The various U. S. government agencies that are pursuing in-space assembly technology have a common need to demonstrate technological capabilities on a space-based platform. Several of the agencies, and different mission developers within an agency, have independently begun planning such demonstrations. This paper reports on a study of how well the different planned platforms could support demonstrations of the agencies' joint needs. The study first prioritized a comprehensive list of the needs for in-space assembly capabilities across the agencies against jointly agreed evaluation criteria. Each planned demonstration platform was characterized to a first order. The capability needs were qualitatively assessed against four figures of merit including their joint priority, and the platforms were assessed against five criteria to produce a quantitative weighting factor of reach capability need and each platform. A Quality Function Deployment (QFD) matrix was used to deploy the weighted capability needs against the weighted platforms capabilities. This first-order assessment showed that the platforms reflect a great deal of redundant capability without a strong reason to prefer one over the others. These results were largely insensitive to the details of the assumptions.
\end{abstract}

\section{I.Introduction}

\section{A. Background}

The space-faring agencies of the US government formed a Space Science and Technology (S\&T) Partnership Forum to explore key, pervasive, and game-changing space technology development efforts of common interest in the hope of making more efficient use of government resources. The partners of the S\&T Partnership Forum, namely the U.S. Air Force, National Aeronautics and Space Administration (NASA), National Reconnaissance Office (NRO), Defense Advanced Research Projects Agency (DARPA) and U.S. Naval Research Laboratory (NRL), identified autonomous or semi-autonomous in-space assembly of next-generation spacecraft as an area for such collaboration. They designated NASA's Office of Chief Technologies to coordinate the initial effort at cooperation in this field. In particular, this included studies and analyses to develop a value proposition and strategic framework for cooperation[1], and to identify the technical capabilities needed along with the synergies and gaps in development activities, and to correlate technology development roadmaps[2]. A third major task, reported here, assessed the joint priority across the partners of the technical capabilities needed for in-space assembly and how readily the planned technology demonstration mission systems could demonstrate them. Figure 1 shows the overall flow of the effort, with the purple and blue analysis boxes and lines showing the tasks in this study. All the analyses relied on data generated by members of the S\&T Partnership.

\footnotetext{
${ }^{1}$ Business Development Manager, Space Technology and Exploration Directorate.

${ }^{2}$ Aerospace Engineer, Space Mission Analysis Branch, AIAA Senior Member

3 Telemetry, Tracking and Communications Systems/Security engineer, Space Missions Analysis Branch.

${ }^{4}$ Aerospace Technologist, Atmospheric Flight and Entry Systems Branch; AIAA Associate Fellow.

${ }^{5}$ Senior Engineer, Bryce Space and Technology

${ }^{6}$ Senior Program Manager, Bryce Space and Technology.
} 


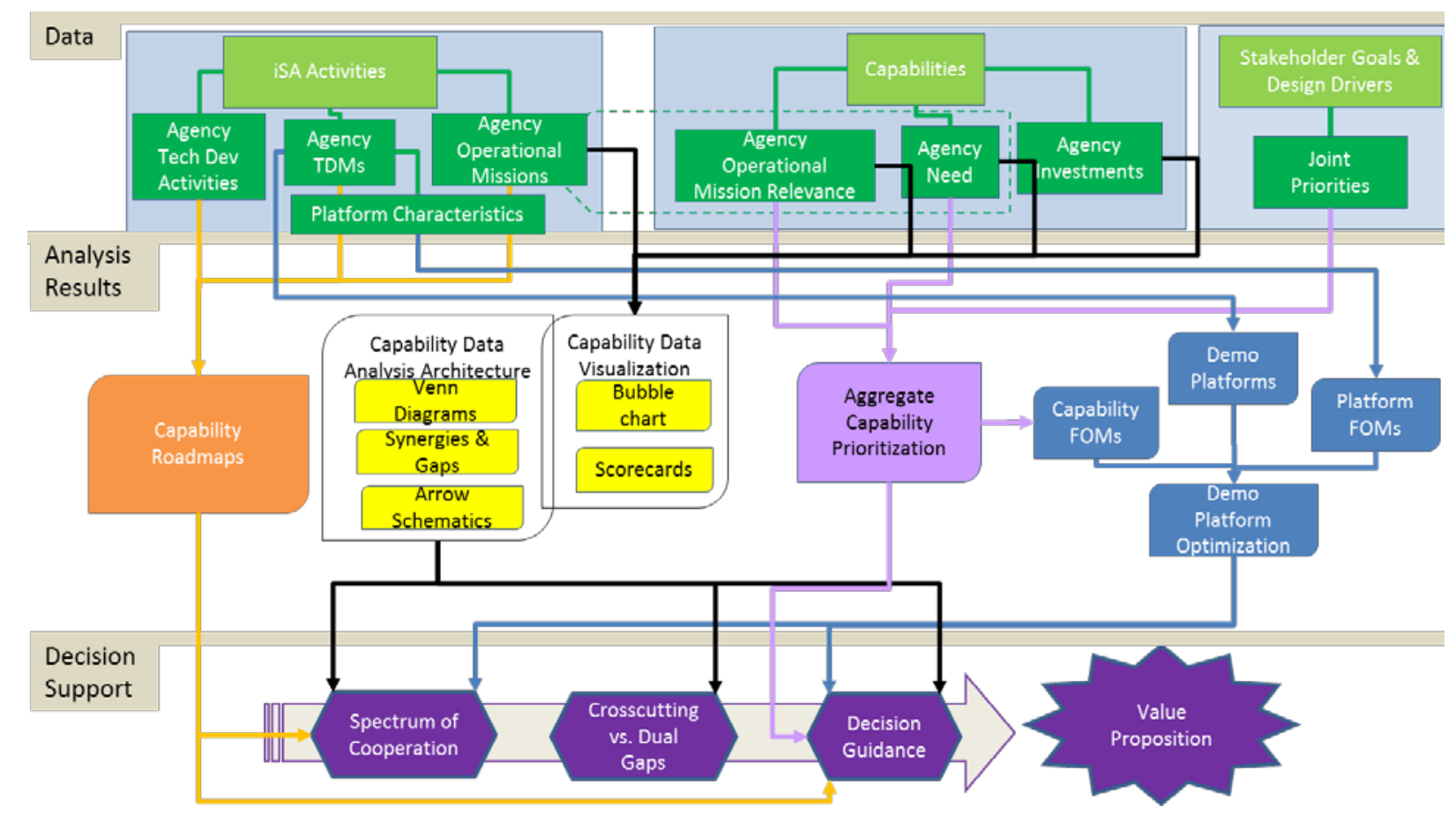

Figure 1: Flow diagram for analyses performed in support of the in-space assembly S\&T Partnership.

\section{B. Study Objectives}

This study sought to assess how well the various space-based platforms in development across the federal agencies could support the demonstration of capability needs that were jointly selected and prioritized by the S\&T Partnership Forum. This included two subordinate objectives:

- Capability Needs Prioritization Objective: Using criteria defined by the agency partners, prioritize a list of in-space assembly capability needs generated by the agency partners to identify which development activities will benefit most from collaboration.

- Demonstration Analysis Objectives: Characterize the various platforms and evaluate how well each would demonstrate the prioritized capability needs.

\section{II.Information Collection and Data Generation}

The information to accomplish this study objective was collected from and/or validated by S\&T Partnership representatives with specific knowledge of their agency's mission needs, program plans, and technology investments. The data collections are shown in the green boxes and arrows in Figure 1. In line with the two subordinate objectives, two major sets of information were collected for this analysis: information to enumerate and prioritize the various technical capabilities that are needed for in-space assembly; information to identify and characterize and compare the various technology demonstration platforms. This information was transformed into the data for analysis by assessing it against quantified evaluation and weighting factors.

\section{A. Data for Capability Needs Prioritization}

The analysis team, in coordination with the agency partners, developed and refined a comprehensive list of the technical capabilities that would be need for in-space assembly and sorted them into fourteen functional categories. These are enumerated and defined in Appendix A, Table 8. The S\&P Partners then developed a list of what they considered the most important qualities of technologies to be demonstrated in space and assessed each capability need against those values. They qualities are as follows:

1. Stakeholder Goals.

Four overarching goals were described by the S\&T Partnership Forum stakeholders as the characteristics and longterm performance targets they most desired from in-space assembly capabilities. 
- Supports near-term demonstration: whether a demonstration or mission could be completed within the next one or two budget cycles,

- Affordable: the ability of a mission to meet budget targets,

- Lower cost: whether the capabilities demonstrated in early missions have the potential to lower the cost of future missions, and

- Industry transition: whether the capabilities demonstrated in missions open up a new market for commercial space entities to pursue.

2. Tier 1 Design Drivers.

The capability needs were considered for their importance in driving operational system designs. Five were recognized as being in the first tier:

- $\quad$ Stability: whether the capability supports the tendency of a system to return to its desired state after being perturbed. Stability can refer to a wide range of characteristics, such as spacecraft pointing stability and thermal stability.

- $\quad$ Assembly: whether the capability supports the ability to join spacecraft or space system components. This includes the capability to disassemble or deconstruct the system and reconfigure it into a new system or spacecraft.

- Upgradeability: whether the capability promotes design choices that allow the insertion of new technologies or enhanced capabilities after launch.

- Scalability: whether an approach allows systems to grow in size while maintaining the same number of distinct parts. For example, a segmented aperture could be scaled up to a size by adding additional segments of the same basic configuration.

- Interfaces: whether the configuration allows independent systems to interact with each other to in simple, predictable ways. Mechanical interfaces transfer a physical quality (structural loads, cargo, electricity, fluids); communication interfaces transfer information (common software, data).

3. Relevance to Operational Missions and Participating Organizations

The partners together identified a total of thirteen planned operational missions that could take advantage of in-space assembly. Each organization rated each capability need as either "enabling," "supporting," or "not applicable" to each of the agency's own missions. They also reported rated their level of investment in the technology for each capability need as "significant," "some," or "none".

4. Cost Factors Associated with Demonstrating the Capability Needs

The above factors were used to prioritize the capability needs across the S\&T Partnership agencies, per the first objective in Section I.B. This prioritization also provides a figure of merit to support the second objective, namely assessing the value of the various platforms for in-space demonstration: a platform's ability to readily accommodate a higher-priority capability need contributed more to its value than its ability to accommodate a lower-priority one. But the platform value also must reflect the costs of demonstrating it in space. Three cost factors were identified for the capability needs:

- Payload cost: the costs of developing and ground testing the payload hardware and software needed to demonstrate the capability need. This accounted for factors such as the payload's complexity, environmental sensitivity, and launch packaging.

- $\quad$ Payload certification costs: the cost of certifying that the payload will not pose an undue hazard to the platform or other platform users.

- $\quad$ Payload launch mass cost factor: the launch costs of the payload considering payload mass as well as any special needs for launch integration.

Separate cost figures of merit, discussed below, were used to account for the differential cost imposed by the platformspecific requirements.

The scope of this study did not allow these cost factors to be assessed in dollar values. Instead, the team established the following broad cost categories reflecting the likely budgetary impacts of funding those elements:

- $\quad$ None: the cost factor for the capability need imposes essentially no costs.

- Minor: the cost factor for the capability would be readily accommodated by routine budget and approval processes.

- Significant: the cost factor for the capability requires the program to get specific budget authority and approval that would not otherwise be needed.

- $\quad$ Major: the factor cost for the capability requires multi-year budget planning and explicit, high-level approval. 
The capability need cost assessments were quantified using the conversions in Table 1 . The priority score, along with the cost factors, were assigned relative weights. The baseline weights for the four factors are provided in Table 2. High scores reflect high value / lower cost.

Table 1: Capability Need Cost Factor Scoring

\begin{tabular}{|c|c|c|c|}
\hline \multicolumn{4}{|c|}{ Cost Evaluation Scoring } \\
\hline None & Minor & Significant & Major \\
\hline 10 & 9 & 4 & 1 \\
\hline
\end{tabular}

Table 2: Capability Need Evaluation Factor Weighting

\begin{tabular}{|c|c|c|c|}
\hline \multicolumn{4}{|c|}{ Factor Weighting } \\
\hline Priority & $\begin{array}{c}\text { Development } \\
\text { Cost }\end{array}$ & $\begin{array}{c}\text { Certification } \\
\text { Cost }\end{array}$ & $\begin{array}{c}\text { Launch } \\
\text { Mass Cost }\end{array}$ \\
\hline 5 & 3.5 & 1 & 4 \\
\hline
\end{tabular}

\section{B. Demonstration Platform Characteristics}

The partner agencies have plans to demonstrate in-space assembly on various platform. The possibility of using the International Space Station for technology demonstration, though not being actively planned, was also considered. Each demonstration platform was investigated by surveying publically available information and talking to subject matter experts in order to characterize its capabilities and limitations, its strengths and weaknesses.

1. The International Space Station.

The International Space Station (ISS) offers a large physical structure in low earth orbit that provides docking and berthing access for crew and cargo vehicles, all routine spacecraft platform services, and, uniquely, crew access via robotics or EVA. It is routinely visited by commercially-operated cargo vehicles. ISS is equipped with five external mounting locations with power and data connections. It has a long reach $(20 \mathrm{~m})$ arm that accommodates a dexterous manipulator but has limited precision. ISS's Japanese Experimental Module also has external exposure access and two robotic arms, one with fine precision, but limited volumetric capacity. ISS's relatively low altitude allows the possibility of remote operation on board. Although

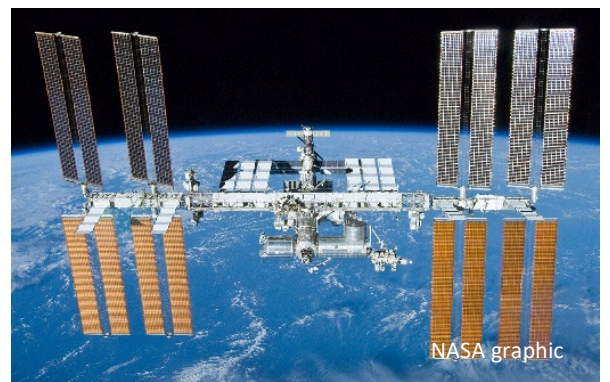

Figure 2: the International Space Station ISS has significant capacity for external payloads, certification costs, availability, and the challenges of off-nominal operations complicate its use as a demonstration platform for in-space assembly. As a crewed platform, ISS imposes stringent safety requirements that increase the cost of certifying a payload relative to uncrewed platforms. NASA has announced plans to decommission ISS in the mid-2020s, but plans for commercializing it are also being considered.

\section{James Web Space Telescope (JWST) Pathfinder}

The JWST Pathfinder is a ground test article that was used to shake out the assembly of the JWST backplane. It consists of the structure for the center section and two wings, several mirror blanks, and secondary mirror support structure. For in-space assembly demonstrations, the Pathfinder could be repurposed and installed on ISS to demonstrate assembly of optical systems in space. A spacebased Pathfinder demonstration explicitly expects to demonstrate human assistance to robotic operation. As structural space telescope hardware, Pathfinder, combined with the resources on ISS, is well suited for demonstrating several capabilities for large telescopes or antennas, including precision positioning techniques, edge matching of mirror segments, working between the substrate and mirror, and connecting utilities across joints. However, as existing hardware with a special purpose, it will be difficult to adapt Pathfinder to support demonstrations of other in-space assembly capabilities. Pathfinder

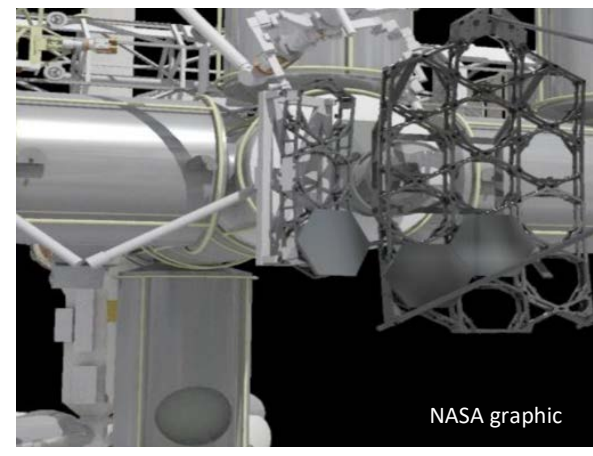

Figure 3: Concept drawing of JWST Pathfinder on ISS would also provide an opportunity to study human and robotic coordination for iSA. 


\section{Restore- $L$}

Restore- $\mathrm{L}$ is an in-space servicing technology demonstration mission being developed by NASA's Space Technology Mission Directorate (STMD), with Space Systems Loral (SSL) as the spacecraft bus provider. Restore-L's mission is to autonomously rendezvous with and service Landsat-7, a satellite in a sun synchronous, low-Earth orbit that was not originally designed to be serviced in space. The mission is currently planned for the mid2020s. In addition to autonomous real-time navigation, rendezvous, and docking, Restore-L includes two dexterous robotic arms and advanced, multifunctional tools to grapple and service the spacecraft and a propellant transfer system to demonstrate refueling. Restore-L's grapple and docking system will allow it to accept delivered modules with new assembly

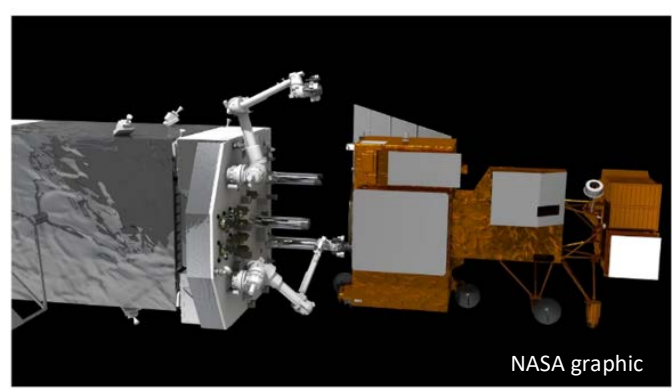

Figure 4: Restore-L servicing demonstration with Landsat-7. demonstration packages. The onboard robotics and autonomy will enable Restore-L to support demonstration of a wide range of in-space assembly capabilities, including the ability to demonstrate new tools via a standard tool interface.

4. Robotic Servicing of Geosynchronous Satellites (RSGS)

The RSGS a public-private partnership between DARPA, Space System Loral (SSL), Tethers Unlimited, and MDA US Systems LLC. DARPA's interest is in demonstrating the technology for satellite servicing in geosynchronous orbit; if successful, SSL intends to use the platform to provide commercial satellite servicing and can also make its capability commercially available for technology demonstrations such as those for in-space assembly. RSGS's core functions include the ability to grapple and manipulate other space vehicles using two robotic arms. It has the ability to change endeffector tools; its toolset is initially limited to those that are specialized for satellite servicing but standard interfaces and other features make it possible to expand its abilities to provide to related functions. Although RSGS's location in geosynchronous orbit makes access to it

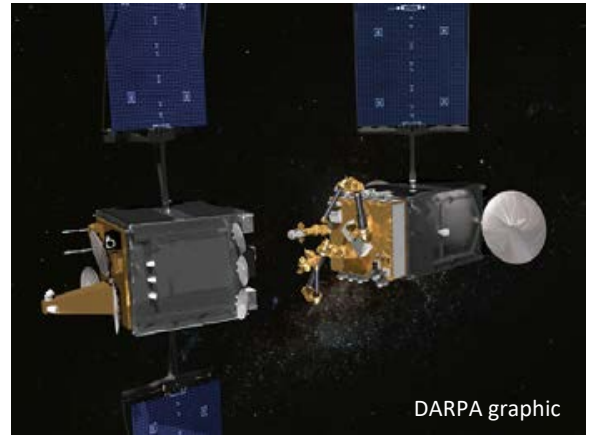

Figure 5: RSGS Platform for satellite servicing and technology demonstrations. more costly than to the other platforms considered, we note that DARPA has also a demonstrated a system called Payload On-board Delivery System (PODS), which is configured to take advantage of rideshare opportunities to geosynchronous orbit in a cost-effective way, somewhat mitigating this disadvantage.

5. Commercial Infrastructure for Robotic Assembly and Servicing (CIRAS)

CIRAS is a proposed public-private partnership between NASA, NRL, and Space Logistics Service, LLC, a subsidiary of NorthrupGrumman (formerly Orbital-ATK). It is configured to demonstrate key technologies for robotic assembly and servicing, especially a long reach, light weight robotic arm capable of precision action at a distance. The CIRAS technology demonstration mission would be based on a Cygnus cargo pod that had completed its delivery to ISS but before its destructive reentry to Earth. Space Logistics Services has announced plans to incorporate the technology demonstrated on CIRAS with other technology developed for its satellite servicing Mission Extension Vehicles (MEVs). MEVs would provide synchronous orbit platforms that are capable of supporting in-space assembly technology demonstrations along with their primary mission of satellite servicing. The analysis in this study only includes the capabilities associated with a government-supported

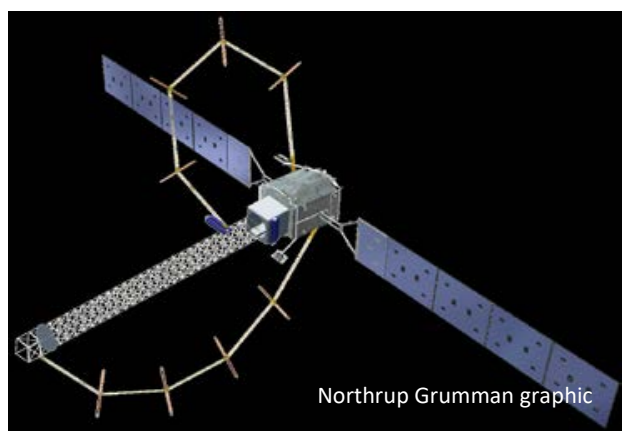

Figure 6: CIRAS Robotic Space Assembly Technology Demonstration Mission CIRAS mission, not the company's plans for privately owned and operated commercial systems.

\section{Platform Figures of Merit}


Two sets of criteria were considered appropriate for assessing the relative value of the different platforms, apart from consideration of their ability to support any particular capability need. The first set consisted of two costs associated with using the platform.

- Platform Access Cost: the cost of getting the payload to the platform's orbital location, including potential discounts for ride-sharing. As distinct from the payload launch mass factor described above, this figure of merit recognizes that the platforms' different orbital altitudes and inclinations, from low earth orbit (ISS, Pathfinder, CIRAS) to sun-synchronous (Restore-L) to geosynchronous (RSGS) impose different launch costs. The survey of website information indicates that launches to geosynchronous orbit are relatively frequent and often have useful mass available for secondary payloads, whereas launches to sun-synchronous orbit are relatively infrequent.

- Certification for Platform Cost: the cost of certifying that the payload will not pose an undue hazard to the platform, other platform users, or other users of the platform's orbital space. As distinct from the payload certification cost, this figure of merit captures the differential cost of certifying a payload for the particular platform. Notably, ISS has stricter certification standards associated with safeguarding human crews and for disposal of external payloads in a way that precludes recontact and does not contribute to orbital debris. This figure of merit originally intended to encompass any costs of preventing compromise to national security assets, but no such costs were identified.

These costs were qualitatively evaluated then quantified using the same metrics used to evaluate the payload costs and quantified per the values in Table 1.

The second set of figures of merit considers the likelihood that the platform will be available for demonstrations. This encompasses of three separate considerations:

- Programmatic Realism: the likelihood that the platform will be physically available to demonstrate the capability needs. Of the platforms under consideration, only ISS is operational at the time of this study. The other platforms' availability depends on continued or new program support, which in turn depends on several factors: the sponsors' commitment to the program; the results of any head-to-head competition; and/or general program funding competition. It is also influenced by commercial partnerships and the commitment of any commercial partner to a business model that depends on the platform's success.

- Timeframe: the likelihood that the platform will be available in a realistic timeframe for demonstrating the capabilities. Among the platforms under consideration, ISS is at risk of being decommissioned in the mid2020s, and CIRAS would be available for only a short period of time. This analysis did not attempt to look at whether individual platforms would be available in a timely way for an individual capability need but instead looked broadly at how the spectrum of needs would align with the anticipated platforms availability in time.

- Access to the Manifest: the likelihood that the manifest for the platform will prioritize demonstration of inspace assembly capabilities. RSGS and ISS have other uses that may compete in priority with such demonstrations. The CIRAS experiment may be too constrained by cost, mass, and/or power to be useful beyond its originally planned manifest.

These availability figures of merit were qualitatively assessed using the following evaluation criteria:

- Certain: greater than $90 \%$ likelihood that the platform will be available.

- $\quad$ Likely: more likely than not that the platform will be available.

- Questionable: about equally as likely as unlikely that the platform will be available.

- Unlikely: the platform is more unlikely than likely to be available.

These availability figures of merit were quantified using the conversions in Table 3.

Table 3: Platform Availability Scoring

\begin{tabular}{|c|c|c|c|}
\hline \multicolumn{4}{|c|}{ Likelihood } \\
\hline \multirow{2}{*}{ Certain } & Likely & Questionable & Unlikely \\
\hline 8 & 6 & 3 & 1 \\
\hline
\end{tabular}

As with the capability needs, the five different platform figures of merit were assigned different weights, which were tested for sensitivity. The baseline values are provided in Table 4 . The platform's value was calculated by multiplying its score for each factor by the factor weight, adding across the factors, the normalizing on a 1 to 0 scale where a higher score reflects a higher value. The values in these two tables were established by the analysis team and reviewed by partnership representatives.
Table 4: Platform Evaluation Factor Weighting

\begin{tabular}{|c|c|c|c|c|}
\hline \multicolumn{5}{|c|}{ Factor Weighting } \\
\hline $\begin{array}{c}\text { Platform } \\
\text { Access } \\
\text { Cost }\end{array}$ & $\begin{array}{c}\text { Certification } \\
\text { Cost for } \\
\text { Platform }\end{array}$ & $\begin{array}{c}\text { Program } \\
\text { Realism }\end{array}$ & Timeframe & $\begin{array}{c}\text { Access to } \\
\text { Manifest }\end{array}$ \\
\hline 2 & 1 & 3 & 2 & 3 \\
\hline
\end{tabular}




\section{III.Analytical Methodology}

The analysis of this data proceeded in two separate steps. The capability need priority assessments were combined to provide a joint priority across the agencies with the commonality noted. The platforms were assessed for their overall ability to support a demonstration of the capability need.

\section{A. Capability Needs Prioritization Methodology}

Each of the 46 capability needs was prioritized by analyzing it against the first three criteria described in Section II.A. The stakeholder goals and tier 1 design drivers were scored on an ordinal scale of 1 to 5 , where 1 reflects a capability that supports this criterion extremely well and 5 a capability does not support this criterion. A capability considered not applicable was evaluated as null. Scores were then aggregated using the average across all the criteria assessed resulting in a final score renormalize on a scale between 0 and 5 .

For the relevance to operational missions, each partner organization rated each the capability need against each of its own operational missions as one of the following:

- Enabling: the particular capability is required for the particular mission.

- Supporting: the particular capability is not required for the particular mission but would improve its performance, cost, or other important consideration,

- $\quad$ Not applicable: the particular capability is not relevant to the particular mission.

Two relevance values were calculated: the percentage of the 13 operational missions for which the capability is enabling; how many of the partner organizations assessed the capability as relevant for at least one of its missions. The relevance of each capability need was categorized as follows:

- Cross-cutting: all three of the partners identified the capability need as either enabling or supporting one of its missions.

- Bilateral: two of the three partners identified the capability need as either enabling or supporting one of its missions.

- $\quad \underline{\text { Unilateral: }}$ only one partner identified the capability need as either enabling or supporting to one of its missions.

To generate a single prioritization score, the criteria were normalized then added. The capability need set was then renormalized by its percentile position converted to a decimal score between 0 and 1 , where 1 is best. The capability needs were ranked by prioritization percentile.

The capability need cost factors described in Section II.A.4 were incorporated separately as part of the assessment of the optimal platform and are not part of the priority figure of merit.

\section{B. Platform Value Analysis Methodology}

The methodology to analyze the usefulness of the platform adapted the Quality Function Deployment (QFD) techniques previously used for a complicated assessment of in-space assembly needs[3]. The generic methodology deploys the qualities to be accommodated, called the WHATS, against the alternative means of accommodating them, called the HOws. In this case, the capability needs were deployed as the WHATS against the various platforms as the HOWs. See Figure 7.

The QFD methodology allows each WHAT and HOW to be weighted by its intrinsic value. The weight for capability needs combined the priority with the cost factors described in Section II.A.4, weighted by the values in Table 2. The weight for the platforms was generated as described in Section II.C and weighted per Table 4. In both cases, the figures of merit were normalized to a scale of 0 to 1 where a higher numerical score reflected higher value.

A classical QFD analysis uses a relatively simple assessment in the matrix between the WHATS and HOWs, often one that reflects only the relevance of the HOW to the WHAT. This analysis sought a finer gradation of relevance, one that described the readiness of the platform as currently understood to accommodate an experimental payload that could demonstrate the capability need. Readiness describes the extent to which the baseline technical capabilities of a platform, along with its baseline budget and deployment schedule, would be affected by making provision for the platform to accommodate a demonstration of the capability need. Five levels of readiness were defined:

- $\quad$ None: the platform can accommodate the need with essentially no modification. This rating was given when a platform was deliberately configured to demonstrate a technology that provides the particular capability 
need receive this rating, or when the demonstration could be accomplished by merely adding a new tool or sensor via a standard interface or by adjusting some control software in non-critical ways.

- Minor: any needed modification is well within the intended technical and/or programmatic scope of the platform and can be accommodated with changes that were anticipated in the baseline.

- Significant: any needed modification is within the technical and/or programmatic scope for the intended use of the platform but would require some recertification and/or revalidation of it.

- Major: the baseline platform configuration would require extensive design and/or certification changes with multi-year programmatic impacts.

- Cannot support: the platform is inherently incapable of accommodating this capability need. If the platform was irrelevant to the capability need, it was scored as null. After the capability need - platform readiness pair was evaluated qualitatively against these criteria, the result was quantified using the values in Table 5.

Table 5: Quantitative Values for Readiness

\begin{tabular}{|c|c|c|c|c|}
\hline \multicolumn{5}{|c|}{ Readiness Scoring } \\
\hline None & Minor & Significant & Major & $\begin{array}{c}\text { Cannot } \\
\text { support }\end{array}$ \\
\hline 10 & 8 & 4 & 1 & 0 \\
\hline
\end{tabular}

Each capability need was interrogated across the platforms to determine which platform had the highest product of readiness rating and platform weight. This was termed the optimal platform for the capability need.

The analysis team considered whether other factors besides readiness ought to be assessed in a matrix between the capability need and the platform rather than rolled up into a weight. For example, the development, launch, or certification cost of a particular payload might vary with the platform. The team considered that, for this first order analysis, the sensitivity to that level of detail would not justify the complications of such a treatment.

\section{Scenarios}

The capability needs list in Appendix A incorporates any capability that any of the S\&T Partnership members identified as potentially relevant. To improve usefulness of the analysis for mission scenarios that needed only in a subset of the capabilities, the analysis incorporated an ability to examine defined mission scenarios. The following three representative scenarios reflect on-going discussions in the community about how in-space assembly could be used in operational mission system of interest to more than one partner agency. Table 10 in Appendix B shows which capability needs apply to each scenario.

- Scenario 1: Large Space Telescope. NASA's JWST reflects that largest telescope ever likely to be completely assembled before launch; its deployment is considered high risk. A larger aperture telescope with a commensurately larger baffle, primary and secondary support structures, power needs, etc. is considered a prime candidate for in-space assembly. Even when the telescope size does not demand assembly on orbit, the capability to do so could reduce mission complexity, launch risks, and potentially costs. This scenario emphasized capabilities that address the telescope's inherent need for high precision and accuracy in its structural tolerances. It would put a premium on assembly from thermally stable materials like advanced composites. The upgradeability that proved its value on the Hubble Space Telescope will likely be incorporated in future systems, demanding accommodations for proximity and even docked operations by visiting vehicles and possibly crew. Such a system is likely to include modular spacecraft subsystems and instruments that may require interface ports.

- $\quad$ Scenario 2: Space Vehicle Hub and Transfer Facility. NASA envisions a lunar or Mars proximity gateway location with the ability for multiple, various vehicles or assets to dock or berth at the facility to transfer equipment, supplies, and samples between vehicles using an astronaut and/or a robot. It would have to be constructed in space due to its complexity and size. Such a facility could ultimately find commercial or military use as a platform for dispatching servicing robots to satellites in a constellation, for example in geosynchronous orbit. Its capability needs emphasize docking and/or berthing, transferring mass including liquids between vehicles, modular design concepts with the ability to handle a variety of sizes, power and data connectivity across the vehicle, and the ability to persist and adapt to unforeseen needs.

- $\quad$ Scenario 3: Communications Hub. Eventual deep space exploration activities and even operations in and around geosynchronous orbit may require an enhanced communications hub and relay capability for continuous communications with and around Earth. A high-bandwidth communications hub could relay communications between deep space and earth-based stations, as well as facilitate space-to-space relay. A mix of antennae would cover the $\mathrm{X}, \mathrm{Ku}, \mathrm{Ka}$ bands as well as optical communication. Getting the most bandwidth, good performance in the lower frequency bands, and sensitivity to low received power signals such as those from deep space may require apertures so large that they have to be constructed in space. Power and cooling for such a hub would also require structures that are not easy to package into a launch 
shroud. Modular growth and upgrade will require attention to architectures and interfaces that allow true plug-n-play capability. Docking and proximity operations must be implemented with particular attention to critical failures and fail-safe operation. A demonstration of this communications hub/relay assembly would likely require the capability needs identified in Appendix B.

\section{IV.Analysis and Results}

\section{A. Capability Needs Prioritization}

Capabilities were ranked based on their final prioritization score without weighting. The top 20 capability needs are shown in Table 6.

Table 6: Top Twenty Capability Needs by Priority

\begin{tabular}{|l|c|c|}
\hline Capability Need & Rank & $\begin{array}{c}\text { Aggregate } \\
\text { Prioritization } \\
\text { Score }\end{array}$ \\
\hline 7.3 Fail-safe modes of behavior on failure detection & 1 & 1.00 \\
\hline 10.3 Modular design & 2 & 0.96 \\
\hline 14.1 Soft docking / berthing of modules & 3 & 0.91 \\
\hline $\begin{array}{l}\text { 13.1 A limited number of standard mechanical, electrical, thermal, and fluid connection } \\
\text { approaches with well-characterized properties }\end{array}$ & 4 & 0.89 \\
\hline 6.1 Standard protocols and ports to accommodate visiting vehicles and communication traffic & 5 & 0.87 \\
\hline 5.1 Means of verifying the continuity of interface connections / disconnections & 6 & 0.84 \\
\hline 10.5 Design for serviceability & 7 & 0.84 \\
\hline 5.5 Modeling and simulation for verification and validation & 8 & 0.83 \\
\hline 5.6 Modeling and simulation for assembly sequencing / planning & 8 & 0.83 \\
\hline 4.1 Ability to reversibly assemble structural, electrical, and fluid connections & 10 & 0.82 \\
\hline $\begin{array}{l}\text { 6.2 Standard but secure communication protocols to accommodate interaction with other (TBD) } \\
\text { associated systems }\end{array}$ & 11 & 0.80 \\
\hline 5.7 Quantitative performance prediction for autonomous systems & 12 & 0.79 \\
\hline 10.4 Design for assembly & 13 & 0.78 \\
\hline 2.5 Ability to assemble high stiffness structures & 14 & 0.78 \\
\hline $\begin{array}{l}\text { 8.2 Known precision limits of any and all assembly agent elements across the assembly site's } \\
\text { environmental envelope }\end{array}$ & 15 & 0.77 \\
\hline 2.1 Robotic assembly with joining & 16 & 0.76 \\
\hline 3.1 Ability to route electrical power and data across assembled joints & 17 & 0.76 \\
\hline $\begin{array}{l}\text { 4.2 Ability to disconnect structural, electrical, and fluid connections without propagating damage } \\
\text { to other system components }\end{array}$ & 18 & 0.73 \\
\hline 3.3 Ability to route fiber optical conductors across joints & 19 & 0.71 \\
\hline 7.1 Intelligence to make stereotyped decisions correctly without human input. & 20 & 0.68 \\
\hline
\end{tabular}

These highest priority needs did not require development and demonstration of futuristic technologies so much as establishing and validating available technologies for these futuristic uses. Needs associated with assembling modules and employing common standards ranked higher than, for example, those associated with robotically building a structure in space. This is an appropriate reflection of the S\&T Partnership's value functions described in Section II.A, which assigned priority to thing that could be demonstrated in the near term.

The results of the prioritization of all the capabilities is given in Appendix A, Table 9. The table also include the other products of this analysis appropriate to the individual capability needs:

- $\quad$ the assessments of the cost figures of merit described in Section II.B.6,

- the intrinsic value score that serves as the capability need weight in the QFD, which was generated using the methodology described in Section II.A.4,

- the commonality assessment described in Section III.A, and

- the optimal platform for demonstrating the individual capability, described below.

\section{B. Demonstration Platform Analysis}




\section{Output Scores}

To analyze the demonstration platform data, three different quantitative scores were generated for each platform.

- Overall platform value function generated by the QFD. This was calculated as described in Section III.B. The results were not normalized.

- $\quad$ High readiness percentage. This determined the percentage of the capability needs that had a readiness rating of "none" or "minor" as defined in Section III.B.

- Optimal platform by count/percentage. This determined the percentage of capability needs that each platform was considered optimal to support. The optimal platform for each capability need is included in Appendix A, Table 9.

The results of these three outputs plus the intrinsic platform value described in Section III.B are shown in Table 7.

Table 7: Platform Assessments

\begin{tabular}{|r|c|c|c|c|c|}
\hline & ISS & Pathfinder & Restore-L & RSGS & CIRAS \\
\hline Platform Intrinsic Value for QFD weight & 0.86 & 0.86 & 0.89 & 0.91 & 0.83 \\
\hline QFD-Generated Platform Value & 19.4 & 14.5 & 21.5 & 22 & 13.1 \\
\hline High Readiness Percentage & $79 \%$ & $51 \%$ & $67 \%$ & $71 \%$ & $51 \%$ \\
\hline Optimal Platform Percentage & $15 \%$ & $13 \%$ & $15 \%$ & $50 \%$ & $13 \%$ \\
\hline
\end{tabular}

Because these results depend on the specific input parameters and encompass different many assumptions, they require careful interpretation. The clustering of values and the qualitative nature of the evaluation suggests that small differences would not be particularly significant. Furthermore, these results reflect the full range of capability need priorities, including low priorities and those that are of interest to only one of the S\&T partners. The analysis team also discovered some ambiguity in the understanding of "readiness," namely whether the platform was ready to provide only spacecraft bus services like power and communication, leaving the full burden of the specific demonstration on the payload, or whether it could provide generic in-space assembly services such as a capable robotic manipulator, thus easing the requirements on the payload. The results above generally reflect the latter; complete resolution of this ambiguity awaits future work.

\section{Filtering}

To improve the usefulness of the analysis, the tool was configured to filter the results in various ways appropriate to a user's specific inquiry. The filters could be used in any combinations.

- $\quad$ Priority percentile categories. The capability need priority score was normalized as percentile. The individual priorities could be binned into a variable number of percentile groups from two halves to ten deciles and the results filtered to include any combination of those percentile groups (e.g. top half, top three quintiles).

- Platforms included: any combination of the five platforms could be considered together with the others excluded.

- Commonality: the results could be filtered to include any combination of commonality as defined in Section III.A: cross-cutting, bilateral, and unilateral.

- $\quad$ Scenario: the result could be filtered to examine only the capability needs required by the selected scenario, as described in Section III.C.

3. Secondary outputs

The analysis was configured primarily to determine which platform produced the highest output score using one of the three scoring criteria described above and considering the filters applied; it also graphically represented how the other platforms scored in comparison. The tool was also set up to reflect other outputs against the same output score and filters:

- Second best platform: the platform with the second highest output score.

- Best complement platform: the platform that had the highest output score considering only those capability needs for which the optimal platform readiness was not evaluate as high, the "none" or "minor" ratings described in Section III.B.

\section{Sensitivity Analysis}

Varying the weighting used to prioritize the capability needs showed the results within the top 20 capabilities in Table 6 to be largely insensitive to changing multiple analytical assumptions.

Sensitivity of the platform value analysis was tested by varying the baseline platform availability assessed against the criteria and scoring shown in Table 3 and the platform figure of merit weighting shown in Table 4. These values generated the platform value used as the weighting in the QFD. To assess the sensitivity to the expected platform 
availability, programmatic realism and timeframe values were set to "certain" for all platforms. To assess the sensitivity of platform access costs to polar and geosynchronous orbits, the availability of rideshare opportunities was set to either "expected" or "certain". Sensitivity to the assumptions of the relative weight of the five figures of merit was tested by setting them all to 1 . Table 8 shows the magnitude of the changes caused by varying these parameters to the baseline platform values.

Table 8: Platform Sensitivity

\begin{tabular}{|r|c|c|c|c|c|}
\hline & \multicolumn{5}{|c|}{ Change in Platform Intrinsic Value Score } \\
\hline & ISS & Pathfinder & Restore-L & RSGS & CIRAS \\
\hline Baseline: QFD-Generated Platform Value & 19.4 & 14.5 & 21.5 & 22 & 13.1 \\
\hline Changes with Assured Availability & +1.1 & +2.4 & +3.4 & +3.5 & +6.7 \\
\hline Changes with Certain Rideshare Availability & 0 & 0 & +2.8 & +4.3 & 0 \\
\hline Equal Weighting of Figures of Merit & -1.1 & -.5 & 0 & +.6 & +1.9 \\
\hline
\end{tabular}

Assuming that all the platforms would be available improves all scores. The magnitude of improvement for each individual platform was largely consistent for with criteria scoring values.

Rideshare benefits the platforms in harder-to-reach orbits. The magnitude of the impact is substantially the same regardless of whether the rideshare was either expected or certain.

Equally weighting the platform figures of merit changed the direction of the individual platforms for both sets of criteria scores. ISS and Pathfinder consistently score worse while the effect on Restore-L, RSGS, and CIRAS depends on the other variables.

Many different combinations of these three criteria were also tested but are not shown. The changes combined in roughly linear (additive) ways. In general, changing these assumptions did not change the designation of the optimal platform or the order of the platforms' value metrics.

Changing the filters did change the order in certain cases. Notably, the mission scenario filter associated with a large space telescope, described in Section III.C, made Pathfinder was optimal, an obvious result since Pathfinder was configured for exactly that scenario. Filtering out the lower priority capability needs improved the relative position of ISS.

\section{V.Conclusion and Future Work}

This study began with a long list of capability needs to support a potentially wide range of operational uses for spacecraft assembled in space. The capability needs that rated the highest in priority were those that showed broad applicability and early availability, which aligns with the goals for in-space assembly technologies established by the stakeholders.

The parameter space used to evaluate the relative merit of the various demonstration platforms included two dimensions, namely the capability needs and platforms, and a total of ten figures of merit, one of which, the capability need priority, was itself composed of multiple evaluation factors. The output could be read in three different ways, with four independent filters, and four different platform value outputs. Many different cuts through the parameter space suggest that in most cases, no demonstration platform is obviously superior to all the others.

Using the analytical tool with its filters set to the needs of a particular user could support decision about which platforms should be considered for more detailed assessment in follow-on studies. It could be interrogated for a specific mission scenario, customized figures of merit, and different platform options. It does not replace a thorough and rigorous analysis of alternative but can guide such an analysis to a productive starting point.

The design understanding of the various platforms was maturing during the course of this study. Future work would update the assessment to be consistent with the latest understanding. Future work should also reduce the ambiguity described in Section IV.B, allowing both interpretations of platform readiness but not mixing them. All the platforms considered in this study were either government-owned and -operated or part of a public-private partnership. Further work could incorporate information from purely private platform if they present themselves for such consideration. 


\section{Appendix A: Capability Needs}

Table 9: Capability Needs Categorization and Definitions

\section{Capability}

1. Deployables

1.1 Deployable subsystems

1.2 Inflatable components

2. Structural Assembly

2.1 Robotic assembly with joining

\subsection{Long-reach manipulation}

2.3 Ability to assemble low mass structures

2.4 Ability to assemble high strength structures

2.5 Ability to assemble high stiffness structures

2.6 Ability to assemble structures with micro-stable joints

2.7 Ability to assemble structures with high dimensional stability

2.8 Ability to assemble structures with near isothermal control

2.9 Ability to assemble structures on planetary surfaces

2.10 Ability to deploy hybrid assembly and in-space fabrication processes such as additive manufacturing.

2.11 Conductive heat transfer across assembled joints

3. Connecting Ancillary Utilities

3.1 Ability to route electrical power and data across assembled joints

3.2 Ability to route coaxial cables across joints

3.3 Ability to route fiber optical conductors across joints

3.4 Ability to route fluids across joints

4. Ability to disjoin

4.1 Ability to reversibly assemble structural, electrical, and fluid connections

4.2 Ability to disconnect structural, electrical, and fluid connections without propagating damage to other system components

\section{Definition}

Structures that go from a stowed/packaged configuration to an operational configuration without external assistance

Any deployable part, component, subsystem, etc. that is unfolded, unfurled, or otherwise moved from its stowed position. E.g.: solar arrays, JWST structure, mirrors, sun shade, etc.. Includes compression members (masts) and tension members (membranes, guy wires, cables) For pressure vessels such as habitats, fuel tanks

Use of a robotic system to attach components, subsystems, or system to each other, including both reversible and irreversible methods (e.g., screwing, latching, welding, brazing, gluing, and any other method)

Use of robotic arms to complete assembly tasks at a distance ( $>3.5 \mathrm{~m}$ ) from the structural base.

Ability to handle, manipulate, and join / unjoin components made from lightweight materials and/or having minimal dimensions (e.g. thickness)

Ability to handle, manipulate, and join / unjoin components made from high strength materials and/or having robust dimensions (e.g. thickness)

Ability to handle, manipulate, and join / unjoin components made from materials that have relatively high stiffness / weight even though they may not have high strength

Ability to join components specifically designed to hold their shape without distortion across their operational lifetime

Ability to use materials and designs that passively resist distortion due to operational mechanical loads

Ability to use materials and designs that passively resist distortion due to thermal loads
Heat transfer limiting factor in many systems and modular heat transfer systems need development both passive and active

"Joint" refers to any interface between components that were joined in space 
5. Sensing, Modeling, Simulation,
Verification

5.1 Means of verifying the continuity of interface connections / disconnections.

5.2 Sensors to accurately and precisely measure the quality of the build-up in progress.

5.3 Sensors to accurately and precisely measure the as-built configuration

5.4 Sensors to detect failures and/or unacceptable quality of the assembly process after it has been completed

5.5 Modeling and simulation for verification and validation

5.6 Modeling and simulation for assembly sequencing / planning

5.7 Quantitative performance prediction for autonomous systems

6. Interoperability

6.1 Standard protocols and ports to accommodate visiting vehicles and communication traffic

6.2 Standard but secure communication protocols to accommodate interaction with other (TBD) associated systems

7. Automation / Autonomy

7.1 Intelligence to make stereotyped decisions correctly without human input

7.2 Intelligence for full autonomy

7.3 Fail-safe modes of behavior on failure detection.

7.4 Multi-agent autonomy (distributed situation assessment \& coordinated control)

\section{Precision}

8.1 Jigging and joining processes capable of achieving a high level of precision open-loop

8.2 Known precision limits of any and all assembly agent elements across the assembly site's environmental envelope

\section{Adaptive Correction}

9.1 Tools and approaches to alter a buildup in progress to correct build up errors

10. Design

10.1 Tools and component parts capable of accommodating a continuous spectrum of design options
Ability to determine, either from in space or on the ground, that the system has been properly assembled and will meet performance specifications

Emphasis on in-progress. Compare with 5.3, which refers to verification and validation after the assembly has been completed

Checking overall conformance to design specifications

Ability to predict with known confidence the statistical performance of autonomous systems operating in uncertain environment. Alternatively, ability to quantify likelihood of system performing counterproductive or destructive operations

Ability of two systems to properly function across an interface

Hardware/operations for interoperability

Software for interoperability

Ability to perform tasks and assess situation for decision making with minimal or no human input

Software to automate assembly operations short of full autonomy, minimal adaptability to unexpected situations

Ability to detect problems and move into "safe mode" to foreclose additional problems

Ability of multiple autonomous agents to develop common situation state estimate \& develop appropriate cooperative plans of action w/out requiring massive real-time data links between agents

Methods for ensuring the precision of the joining process

Primarily related to changes in the thermal environment as the spacecraft orbits

Methods of system design that facilitate assembly

Distinct from limitations based on established sizing of components and tools 
10.2 Assembly agent geometries, Scalability

systems, and tools that do not preclude dimensional or mass growth of the client system

10.3 Modular design

Design with standard interfaces that allows for simple replacement of components and for re-configurability of systems by rearranging modules

10.4 Design for assembly

10.5 Design for serviceability

11. Tunability

11.1 Ability to accommodate structural Ex: JWST primary mirror movement to achieve focus members with active length control

11.2 Ability to accommodate power and data control interfaces associated with active structural members

11.3 Ability to accommodate TBD sensors for length and/or structural geometry 12. Stability

12.1 Ability to accommodate passive vibration damping

13. Standard Interfaces

As a way to increase stability

13.1 A limited number of standard mechanical, electrical, thermal, and fluid connection approaches with wellcharacterized properties

14. Docking/Berthing

14.1 Soft docking / berthing of modules

Common interfaces that will ensure components/systems from different providers will be able to properly connect and function

Standard to other systems, infers that the interface can be available to other space organizations

Joining fully functional modules together either directly (autonomously or teleoperated) or with robotic assistance

Joining of spacecraft or spacecraft modules via a mechanical interface that attenuates any relative motion between modules. The interface is usually a docking ring. Ex: manned-space vehicle docking or joining of ISS pressurized modules. Includes any Rendezvous and Proximity Operations

\begin{tabular}{l} 
15. Human Compatibility \\
$\begin{array}{l}15.1 \text { On-site astronaut assembly } \\
\text { servicing }\end{array}$ \\
\hline $\begin{array}{l}\text { 15.2 Support and Infrastructure - human } \\
\text { interfaces and monitoring }\end{array}$
\end{tabular}


Table 10: Results of Assessment and Analysis of Capability Needs

\begin{tabular}{|c|c|c|c|c|c|c|c|c|c|}
\hline & & Capability Need & $\begin{array}{l}\text { Priority } \\
\text { percentile } \\
(0 \text { to } 1)\end{array}$ & $\begin{array}{l}\text { Payload } \\
\text { Cost } \\
\text { Assessm't }\end{array}$ & $\begin{array}{l}\text { Payload } \\
\text { Cert } \\
\text { Costs } \\
\text { Assessm't }\end{array}$ & $\begin{array}{c}\text { Payload } \\
\text { Launch } \\
\text { Mass Cost } \\
\text { Factor } \\
\text { Assessm't }\end{array}$ & $\begin{array}{l}\text { Normalized } \\
\text { Capability } \\
\text { Need Score } \\
(0 \text { to } 1)\end{array}$ & Commonality & $\begin{array}{l}\text { Optimal } \\
\text { Platform }\end{array}$ \\
\hline \multirow[t]{3}{*}{1} & Deplo & bles & & & & & & & \\
\hline & 1.1 & Deployable subsystems & 0.29 & minor & minor & minor & 0.67 & Crosscutting & RSGS \\
\hline & 1.2 & Inflatable components & 0.12 & significant & significant & minor & 0.45 & Bilateral & RSGS \\
\hline \multicolumn{10}{|c|}{$\begin{array}{ll}2 & \text { Structural Assembly }\end{array}$} \\
\hline & 2.1 & Robotic assembly with joining & 0.74 & minor & minor & minor & 0.84 & Crosscutting & Restore-L \\
\hline & 2.2 & Long-reach manipulation & 0.42 & minor & significant & minor & 0.69 & Unilateral & ISS \\
\hline & 2.3 & $\begin{array}{l}\text { Ability to assemble low mass } \\
\text { structures }\end{array}$ & 0.58 & minor & minor & minor & 0.78 & Crosscutting & RSGS \\
\hline & 2.4 & $\begin{array}{l}\text { Ability to assemble high strength } \\
\text { structures }\end{array}$ & 0.38 & minor & minor & minor & 0.71 & Crosscutting & RSGS \\
\hline & 2.5 & $\begin{array}{l}\text { Ability to assemble high stiffness } \\
\text { structures }\end{array}$ & 0.75 & minor & minor & minor & 0.84 & Crosscutting & RSGS \\
\hline & 2.6 & $\begin{array}{l}\text { Ability to assemble structures } \\
\text { with micro-stable joints }\end{array}$ & 0.41 & minor & minor & minor & 0.72 & Bilateral & Restore-L \\
\hline & 2.7 & $\begin{array}{l}\text { Ability to assemble structures } \\
\text { with high dimensional stability }\end{array}$ & 0.41 & minor & minor & minor & 0.72 & Crosscutting & Restore-L \\
\hline & 2.8 & $\begin{array}{l}\text { Ability to assemble structures } \\
\text { with near isothermal control }\end{array}$ & 0.49 & minor & minor & minor & 0.75 & Bilateral & Restore-L \\
\hline & 2.9 & $\begin{array}{l}\text { Ability to assemble structures on } \\
\text { planetary surfaces (e.g. Moon, } \\
\text { Mars) }\end{array}$ & 0.06 & major & significant & major & 0.11 & Unilateral & Pathfinder \\
\hline & 2.10 & $\begin{array}{l}\text { Ability to deploy hybrid assembly } \\
\text { and in-space fabrication processes } \\
\text { such as additive manufacturing. }\end{array}$ & 0.40 & significant & minor & minor & 0.58 & Bilateral & Restore-L \\
\hline & 2.11 & $\begin{array}{l}\text { Conductive heat transfer across } \\
\text { assembled joints }\end{array}$ & 0.46 & minor & minor & minor & 0.74 & Crosscutting & Restore-L \\
\hline \multicolumn{10}{|c|}{$3 \quad$ Connecting ancillary utilities } \\
\hline & 3.1 & $\begin{array}{l}\text { Ability to route power and data } \\
\text { across assembled joints }\end{array}$ & 0.73 & minor & minor & minor & 0.84 & Crosscutting & RSGS \\
\hline & 3.2 & $\begin{array}{l}\text { Ability to route RF signals across } \\
\text { joints }\end{array}$ & 0.49 & minor & minor & minor & 0.75 & Unilateral & RSGS \\
\hline & 3.3 & $\begin{array}{l}\text { Ability to route fiber optical } \\
\text { conductors across joints }\end{array}$ & 0.68 & minor & minor & minor & 0.82 & Bilateral & CIRAS \\
\hline & 3.4 & $\begin{array}{l}\text { Ability to route fluids across } \\
\text { joints }\end{array}$ & 0.47 & significant & minor & significant & 0.46 & Crosscutting & Restore-L \\
\hline \multicolumn{10}{|c|}{$\begin{array}{ll}4 & \text { Ability to disjoin } \\
\end{array}$} \\
\hline & 4.1 & $\begin{array}{l}\text { Ability to reversibly assemble } \\
\text { structural, electrical, and fluid } \\
\text { connections. }\end{array}$ & 0.80 & minor & minor & minor & 0.86 & Crosscutting & Restore-L \\
\hline & 4.2 & $\begin{array}{l}\text { Ability to disconnect structural, } \\
\text { electrical, and fluid connections } \\
\text { without propagating damage to } \\
\text { other system components. }\end{array}$ & 0.70 & minor & significant & minor & 0.79 & Crosscutting & Restore-L \\
\hline \multicolumn{10}{|c|}{5 Sensing, Modeling, Simulation, Verification } \\
\hline & 5.1 & $\begin{array}{l}\text { Means of verifying the continuity } \\
\text { of interface connections / } \\
\text { disconnections. }\end{array}$ & 0.82 & significant & minor & minor & 0.74 & Crosscutting & RSGS \\
\hline & 5.2 & $\begin{array}{l}\text { Sensors to accurately and } \\
\text { precisely measure the quality of } \\
\text { the build-up in progress. }\end{array}$ & 0.48 & minor & none & minor & 0.75 & Crosscutting & RSGS \\
\hline & 5.3 & $\begin{array}{l}\text { Sensors to accurately and } \\
\text { precisely measure the as-built } \\
\text { configuration. }\end{array}$ & 0.48 & minor & none & minor & 0.75 & Crosscutting & RSGS \\
\hline & 5.4 & $\begin{array}{l}\text { Sensors to detect failures and/or } \\
\text { unacceptable quality of the } \\
\text { assembly process after it has been } \\
\text { completed. }\end{array}$ & 0.59 & minor & none & minor & 0.79 & Crosscutting & RSGS \\
\hline & 5.5 & $\begin{array}{l}\text { Modeling and Simulation for } \\
\text { Verification and Validation }\end{array}$ & 0.81 & minor & none & none & 0.9 & Crosscutting & Restore-L \\
\hline & 5.6 & $\begin{array}{l}\text { Modeling and Simulation for } \\
\text { assembly sequencing / planning }\end{array}$ & 0.81 & significant & minor & none & 0.77 & Crosscutting & Restore-L \\
\hline & 5.7 & $\begin{array}{l}\text { Quantitative Performance } \\
\text { Prediction for Autonomous } \\
\text { Systems }\end{array}$ & 0.76 & significant & significant & none & 0.71 & Bilateral & Restore-L \\
\hline
\end{tabular}


Table 10: Results of Assessment and Analysis of Capability Needs

\begin{tabular}{|c|c|c|c|c|c|c|c|c|c|}
\hline & & Capability Need & $\begin{array}{l}\text { Priority } \\
\text { percentile } \\
(0 \text { to } 1)\end{array}$ & $\begin{array}{c}\text { Payload } \\
\text { Cost } \\
\text { Assessm't }\end{array}$ & $\begin{array}{l}\text { Payload } \\
\text { Cert } \\
\text { Costs } \\
\text { Assessm't }\end{array}$ & $\begin{array}{c}\text { Payload } \\
\text { Launch } \\
\text { Mass Cost } \\
\text { Factor } \\
\text { Assessm't } \\
\end{array}$ & $\begin{array}{l}\text { Normalized } \\
\text { Capability } \\
\text { Need Score } \\
\left(\begin{array}{l}0 \text { to } 1) \\
\end{array}\right.\end{array}$ & Commonality & $\begin{array}{r}\text { Optimal } \\
\text { Platform }\end{array}$ \\
\hline \multicolumn{10}{|c|}{$6 \quad$ Interoperability } \\
\hline & 6.1 & $\begin{array}{l}\text { Standard protocols and ports to } \\
\text { accommodate visiting vehicles } \\
\text { and communication traffic. }\end{array}$ & 0.86 & none & minor & none & 0.94 & Crosscutting & RSGS \\
\hline & 6.2 & $\begin{array}{l}\text { Standard but secure } \\
\text { communication protocols to } \\
\text { accommodate interaction with } \\
\text { other (TBD) associated systems. }\end{array}$ & 0.77 & none & minor & none & 0.91 & Crosscutting & Restore-L \\
\hline & 6.3 & $\begin{array}{l}\text { Assembled Payload Information } \\
\text { Assurance: Security of } \\
\text { information routing to a persistent } \\
\text { platform bus from one or more } \\
\text { assembled payloads }\end{array}$ & & minor & minor & minor & 0.57 & & Restore-L \\
\hline \multicolumn{10}{|c|}{$7 \quad$ Automation / Autonomy } \\
\hline & 7.1 & $\begin{array}{l}\text { Intelligence to make stereotyped } \\
\text { decisions correctly without human } \\
\text { input. }\end{array}$ & 0.64 & minor & minor & none & 0.83 & Bilateral & Restore-L \\
\hline & 7.2 & Intelligence for full autonomy & 0.32 & significant & significant & minor & 0.52 & Bilateral & Restore-L \\
\hline & 7.3 & $\begin{array}{l}\text { Fail-safe modes of behavior on } \\
\text { failure detection. }\end{array}$ & 1.00 & minor & minor & minor & 0.94 & Crosscutting & RSGS \\
\hline & 7.4 & $\begin{array}{l}\text { Multi-Agent Autonomy } \\
\text { (Distributed Situation Assessment } \\
\text { \& Coordinated Control) } \\
\end{array}$ & 0.27 & significant & significant & minor & 0.5 & Bilateral & RSGS \\
\hline \multicolumn{10}{|c|}{$8 \quad$ Precision } \\
\hline & 8.1 & $\begin{array}{l}\text { Jigging and joining processes } \\
\text { capable of achieving a high level } \\
\text { of precision open-loop. }\end{array}$ & 0.47 & minor & minor & minor & 0.74 & Bilateral & RSGS \\
\hline & 8.2 & $\begin{array}{l}\text { Known precision limits of any and } \\
\text { all assembly agent elements } \\
\text { across the assembly site's } \\
\text { environmental envelope }\end{array}$ & 0.74 & significant & minor & significant & 0.56 & Bilateral & RSGS \\
\hline \multicolumn{10}{|c|}{$9 \quad$ Adaptive Correction } \\
\hline & 9.1 & $\begin{array}{l}\text { Tools and approaches to alter a } \\
\text { build-up in progress to correct } \\
\text { build up errors. }\end{array}$ & 0.55 & significant & minor & significant & 0.49 & Bilateral & RSGS \\
\hline \multicolumn{10}{|c|}{10 Design } \\
\hline & 10.1 & $\begin{array}{l}\text { Tools and component parts } \\
\text { capable of accommodating a } \\
\text { continuous spectrum of design } \\
\text { options. }\end{array}$ & 0.57 & minor & minor & minor & 0.78 & Crosscutting & RSGS \\
\hline & 10.2 & $\begin{array}{l}\text { Assembly agent geometries, } \\
\text { systems, and tools that do not } \\
\text { preclude dimensional or mass } \\
\text { growth of the client system. }\end{array}$ & 0.05 & none & none & none & 0.65 & Crosscutting & RSGS \\
\hline & 10.3 & Modular Design & 0.96 & significant & minor & minor & 0.79 & Crosscutting & RSGS \\
\hline & 10.4 & Design for Assembly & 0.75 & none & none & none & 0.91 & Crosscutting & RSGS \\
\hline & 10.5 & Design for Serviceability & 0.82 & none & none & none & 0.93 & Crosscutting & RSGS \\
\hline \multicolumn{10}{|c|}{$11 \quad$ Tunability } \\
\hline & 11.1 & $\begin{array}{l}\text { Ability to accommodate structural } \\
\text { members with active length } \\
\text { control. }\end{array}$ & 0.00 & minor & none & minor & 0.57 & Crosscutting & RSGS \\
\hline & 11.2 & $\begin{array}{l}\text { Ability to accommodate power } \\
\text { and data control interfaces } \\
\text { associated with active structural } \\
\text { members. }\end{array}$ & 0.27 & minor & none & minor & 0.67 & Crosscutting & RSGS \\
\hline & 11.3 & $\begin{array}{l}\text { Ability to accommodate TBD } \\
\text { sensors for length and/or } \\
\text { structural geometry. }\end{array}$ & 0.24 & minor & none & minor & 0.66 & Crosscutting & RSGS \\
\hline \multicolumn{10}{|c|}{$12 \quad$ Stability } \\
\hline & 12.1 & $\begin{array}{l}\text { Ability to accommodate passive } \\
\text { vibration damping. }\end{array}$ & 0.55 & minor & minor & minor & 0.77 & Crosscutting & RSGS \\
\hline \multicolumn{10}{|c|}{$13 \quad$ Standard Interfaces } \\
\hline & 13.1 & $\begin{array}{l}\text { A limited number of standard } \\
\text { mechanical, electrical, thermal, } \\
\text { and fluid connection approaches } \\
\text { with well-characterized } \\
\text { properties. }\end{array}$ & 0.87 & minor & none & minor & 0.9 & Crosscutting & RSGS \\
\hline \multicolumn{10}{|c|}{14 Docking/Berthing } \\
\hline & 14.1 & Soft docking / berthing of modules & 0.90 & & & & 0.9 & Crosscutting & RSGS \\
\hline
\end{tabular}


Table 10: Results of Assessment and Analysis of Capability Needs

\begin{tabular}{|c|c|c|c|c|c|c|c|c|c|}
\hline \multicolumn{3}{|r|}{ Capability Need } & $\begin{array}{c}\text { Priority } \\
\text { percentile } \\
(0 \text { to } 1)\end{array}$ & $\begin{array}{l}\text { Payload } \\
\text { Cost } \\
\text { Assessm't }\end{array}$ & $\begin{array}{c}\text { Payload } \\
\text { Cert } \\
\text { Costs } \\
\text { Assessm't }\end{array}$ & $\begin{array}{l}\text { Payload } \\
\text { Launch } \\
\text { Mass Cost } \\
\text { Factor } \\
\text { Assessm't }\end{array}$ & $\begin{array}{l}\text { Normalized } \\
\text { Capability } \\
\text { Need Score } \\
\text { (0 to 1) }\end{array}$ & Commonality & $\begin{array}{l}\text { Optimal } \\
\text { Platform }\end{array}$ \\
\hline \multicolumn{10}{|c|}{ Human Compatibility } \\
\hline & 15.1 & $\begin{array}{l}\text { On-site astronaut assembly / } \\
\text { servicing }\end{array}$ & 0.06 & & & & 0.06 & Unilateral & ISS \\
\hline & 15.2 & $\begin{array}{l}\text { Support and infrastructure- human } \\
\text { interfaces and monitoring }\end{array}$ & & & & & 0 & Unilateral & \\
\hline
\end{tabular}




\section{Appendix B: Mission Scenarios}

Table 11: Capability Needs for Mission Scenarios Appropriate for In-Space Assembly

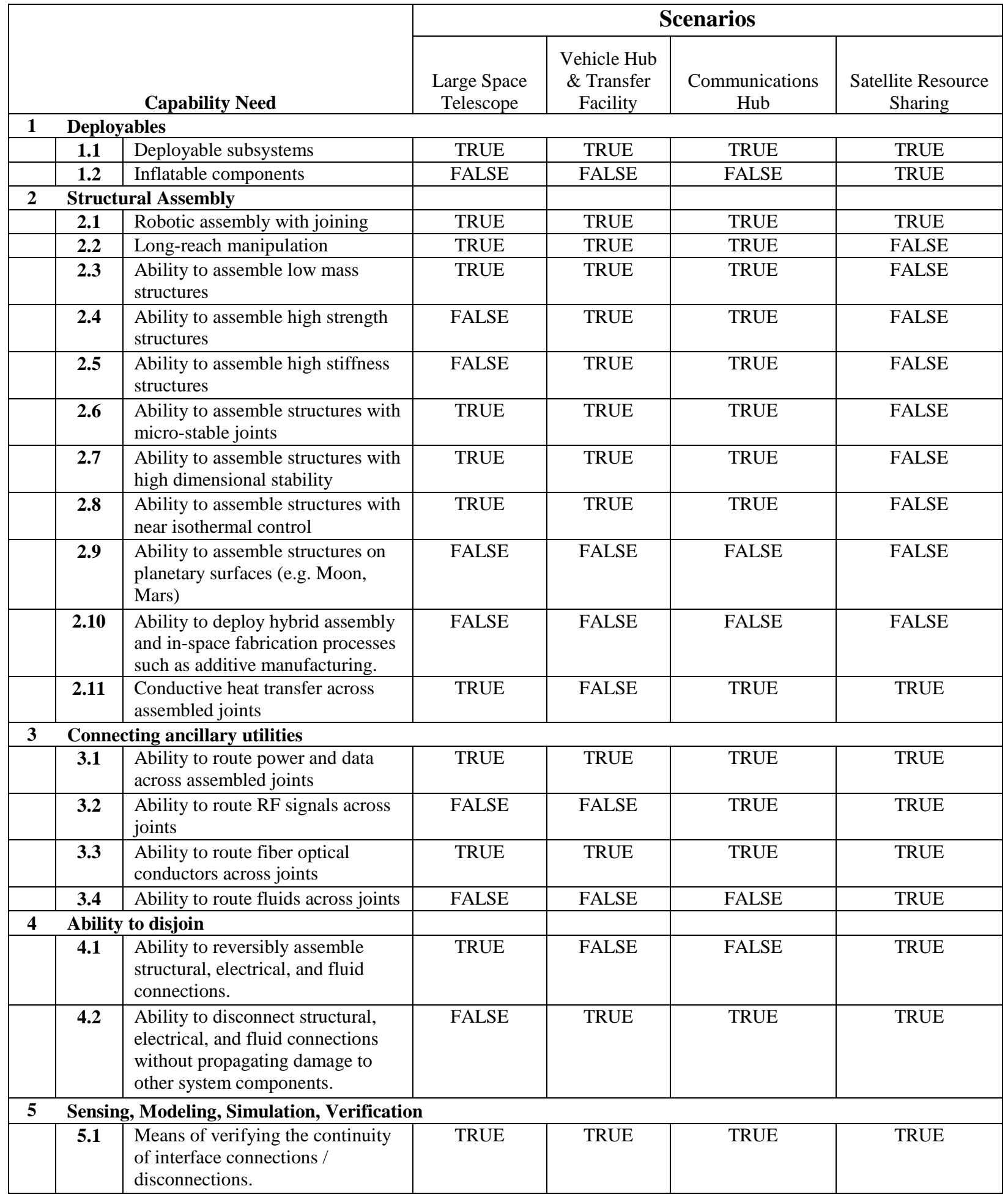


Table 11: Capability Needs for Mission Scenarios Appropriate for In-Space Assembly

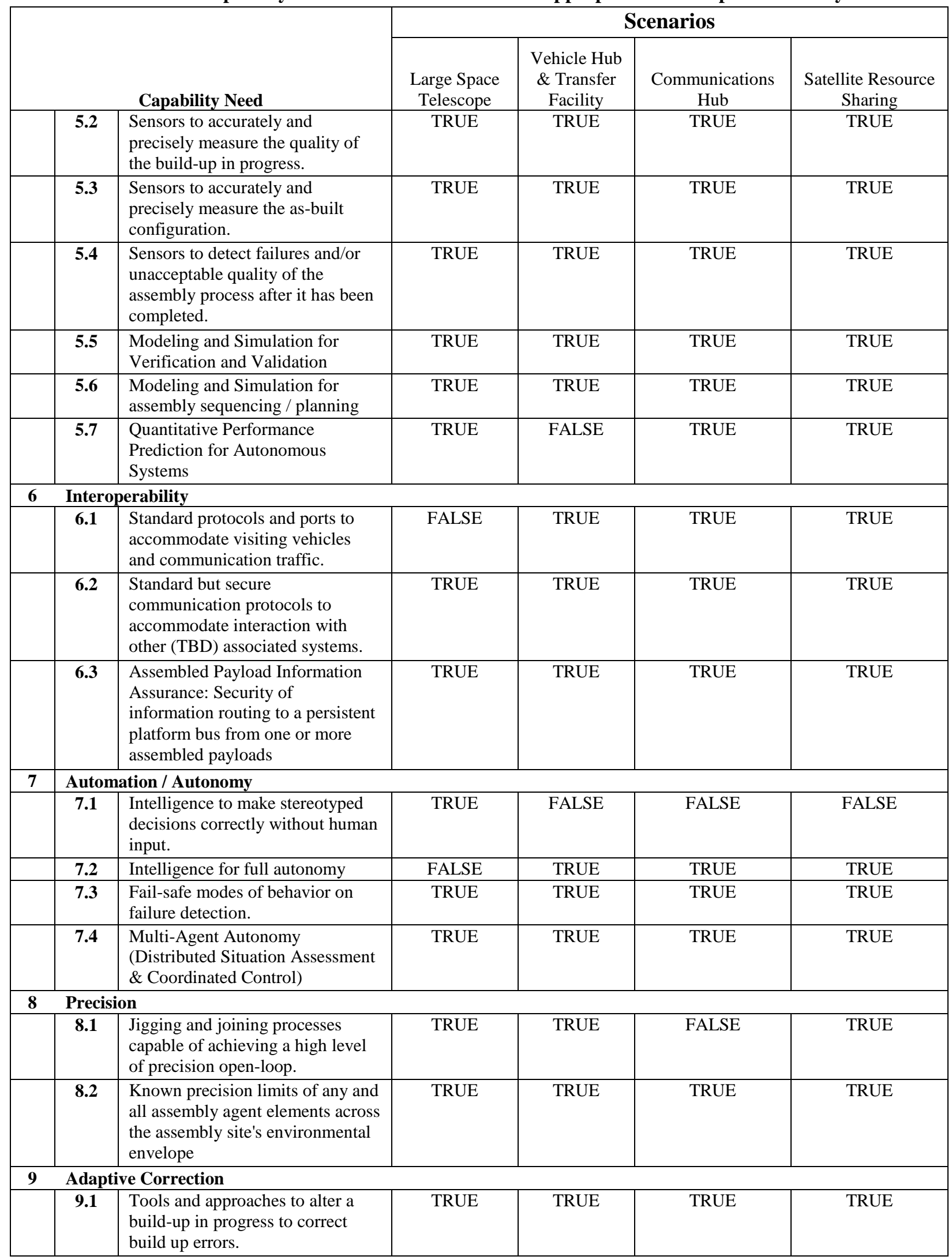


Table 11: Capability Needs for Mission Scenarios Appropriate for In-Space Assembly

\begin{tabular}{|c|c|c|c|c|c|c|}
\hline & & \multirow[b]{2}{*}{ Capability Need } & \multicolumn{4}{|c|}{ Scenarios } \\
\hline & & & $\begin{array}{l}\text { Large Space } \\
\text { Telescope }\end{array}$ & $\begin{array}{l}\text { Vehicle Hub } \\
\text { \& Transfer } \\
\text { Facility }\end{array}$ & $\begin{array}{l}\text { Communications } \\
\text { Hub }\end{array}$ & $\begin{array}{l}\text { Satellite Resource } \\
\text { Sharing }\end{array}$ \\
\hline \multicolumn{7}{|c|}{$\begin{array}{ll}10 & \text { Design } \\
\end{array}$} \\
\hline & 10.1 & $\begin{array}{l}\text { Tools and component parts } \\
\text { capable of accommodating a } \\
\text { continuous spectrum of design } \\
\text { options. }\end{array}$ & TRUE & TRUE & TRUE & FALSE \\
\hline & 10.2 & $\begin{array}{l}\text { Assembly agent geometries, } \\
\text { systems, and tools that do not } \\
\text { preclude dimensional or mass } \\
\text { growth of the client system. }\end{array}$ & TRUE & FALSE & FALSE & FALSE \\
\hline & 10.3 & Modular Design & TRUE & TRUE & TRUE & TRUE \\
\hline & 10.4 & Design for Assembly & TRUE & TRUE & TRUE & TRUE \\
\hline & 10.5 & Design for Serviceability & TRUE & TRUE & TRUE & TRUE \\
\hline \multicolumn{7}{|c|}{$\begin{array}{ll}1 & \text { Tunability } \\
\end{array}$} \\
\hline & 11.1 & $\begin{array}{l}\text { Ability to accommodate structural } \\
\text { members with active length } \\
\text { control. }\end{array}$ & TRUE & FALSE & FALSE & FALSE \\
\hline & 11.2 & $\begin{array}{l}\text { Ability to accommodate power } \\
\text { and data control interfaces } \\
\text { associated with active structural } \\
\text { members. }\end{array}$ & TRUE & FALSE & TRUE & FALSE \\
\hline & 11.3 & $\begin{array}{l}\text { Ability to accommodate TBD } \\
\text { sensors for length and/or structural } \\
\text { geometry. }\end{array}$ & FALSE & TRUE & TRUE & FALSE \\
\hline \multicolumn{7}{|c|}{$\begin{array}{ll}12 & \text { Stability }\end{array}$} \\
\hline & 12.1 & $\begin{array}{l}\text { Ability to accommodate passive } \\
\text { vibration damping. }\end{array}$ & TRUE & TRUE & TRUE & TRUE \\
\hline \multicolumn{7}{|c|}{13 Standard Interfaces } \\
\hline & 13.1 & $\begin{array}{l}\text { A limited number of standard } \\
\text { mechanical, electrical, thermal, } \\
\text { and fluid connection approaches } \\
\text { with well-characterized properties. }\end{array}$ & FALSE & TRUE & TRUE & TRUE \\
\hline \multicolumn{7}{|c|}{14 Docking/Berthing } \\
\hline & 14.1 & Soft docking / berthing of modules & FALSE & TRUE & FALSE & TRUE \\
\hline \multicolumn{7}{|c|}{$15 \quad$ Human Compatibility } \\
\hline & 15.1 & $\begin{array}{l}\text { On-site astronaut assembly / } \\
\text { servicing }\end{array}$ & TRUE & TRUE & TRUE & FALSE \\
\hline & 15.2 & $\begin{array}{l}\text { Support and infrastructure- human } \\
\text { interfaces and monitoring }\end{array}$ & TRUE & TRUE & TRUE & FALSE \\
\hline
\end{tabular}




\section{References}

[1] Williams, P.A., Dempsey, J., Hamill, D.L., Rodgers, E., Mullins, C., Gresham, E, Downs, S., "Space Science \& Technology Partnership Forum: Value Proposition, Strategic Framework, and Capability Needs for In-Space Assembly,” AIAA SPACE 2018, AIAA, Orlando, FL, Sept 17-19, 2018.

[2] Arney, D. C., et al., "Space Science and Technology Partnership Forum: In-Space Assembly Data Collection and Analysis,” AIAA SPACE 2018, AIAA, Orlando, FL, Sept 17-19, 2018.

[3] Hamill, D., Bowman, L., Gilman, D. A., Belvin, W. K., "High Leverage Technologies for In-Space Assembly of Complex Structures,” AIAA SPACE 2016 , AIAA, Long Beach, CA, Sept 13-16, 2016, p. 5397. 